\title{
Reply to Letter to the Editor: "Improved trunk and neck control after selective dorsal rhizotomy in children with spastic cerebral palsy" by Tacchino et al. (2020)
}

\author{
Albert $\mathrm{Tu}^{1}$ (D) \\ Received: 4 October 2020 / Accepted: 5 November 2020 / Published online: 12 November 2020
}

(C) Springer-Verlag GmbH Germany, part of Springer Nature 2020

\section{Dear Editor:}

We read with great interest the submission by Tacchino et al. (2020) and compliment the authors for their thoughtful review of their experience. We do think that the results presented on changes in sitting ability are an invaluable piece of information for both clinicians and patients seeking opinion on the potential role of selective dorsal rhizotomy (SDR) in the management of hypertonicity. As other authors have previously pointed out, much of the literature on SDR remains focused on ambulation and movement while ancillary outcomes such as sitting ability are not often reported. These measures may have a significant impact on quality of life and are worthy of scientific evaluation. While the follow-up in this study remains relatively short, we do feel that the information presented supports the role of SDR in appropriately selected patients. We look forward to future studies that further expand the scope of measureable patient outcomes after SDR.

\section{Compliance with ethical standards}

Conflict of interest On behalf of all authors, the corresponding author states that there is no conflict of interest.

Publisher's note Springer Nature remains neutral with regard to jurisdictional claims in published maps and institutional affiliations.
Albert Tu

atu@cheo.on.ca

1 Division of Neurosurgery, Children's Hospital of Eastern Ontario, Ottawa, ON, Canada 